\title{
Paper
}

\section{New Green and Red Phosphors for White LEDs}

\author{
Naoto KIJIMA, Yasuo SHIMOMURA, Tomoyuki KURUSHIMA, Hiromu WATANABE, \\ Satoshi SHIMOOKA, Masayoshi MIKAMI and Kyota UHEDA
}

Mitsubishi Chemical Group Science and Technology Research Center, Inc.

Received December 18, 2007, Accepted January 21, 2008

\begin{abstract}
High-luminous green phosphors and a red phosphor have been newly developed for white LEDs. The developed green phosphors are $\mathrm{Ca}_{3}(\mathrm{Sc}, \mathrm{Mg})_{2} \mathrm{Si}_{3} \mathrm{O}_{12}$ : $\mathrm{Ce}$ made by replacing with $\mathrm{Mg}$ a part of $\mathrm{Sc}$ of green phosphor $\mathrm{Ca}_{3} \mathrm{Sc}_{2} \mathrm{Si}_{3} \mathrm{O}_{12}: \mathrm{Ce}$, a new green phosphor $\mathrm{CaSc}_{2} \mathrm{O}_{4}: \mathrm{Ce}$, and a new host material doped with a rare-earth element, $\mathrm{Ba}_{3} \mathrm{Si}_{6} \mathrm{O}_{12} \mathrm{~N}_{2}:$ :Eu. The new red phosphor is ( $\left.\mathrm{Sr}, \mathrm{Ca}\right) \mathrm{AlSiN}_{3}$ :Eu made by replacing a part of $\mathrm{Ca}$ of $\mathrm{CaAlSiN}_{3}$ : Eu with $\mathrm{Sr}$.
\end{abstract}

KEYWORDS: phosphor, LED, LCD, lighting, display, backlight, color rendering, color reproducibility

\section{Introduction}

A white LED is mainly used as a liquid crystal display (LCD) back-light source for cellular phones etc. since its size is small and its luminous efficacy is high. In the white LED, a GaN based blue LED is the light source which excites $(\mathrm{Y}, \mathrm{Gd})_{3} \mathrm{Al}_{5} \mathrm{O}_{12}: \mathrm{Ce}$ (YAG) yellow phosphor. Pseudo-white light is obtained by the color mixture of blue light from the blue LED and yellow light from the phosphor.

Intensive research is being carried out to use a white LED as a light source for not only lighting but a large-sized LCD TV with a high luminous efficacy and no toxic substances such as mercury. In order to use a white LED as a light source for the LCD TV or lighting application, it is required to extend color reproducibility or to improve color rendering besides increasing the output power from the white LED, so that the color of an object under light from the LED may look like that under natural light.

For this reason, a new type of white LED emitting tri-color light from a blue LED, a green phosphor and a red phosphor has been developed and is now produced commercially. This paper reports the newly developed phosphors which can be used for the white LED.

\section{Green phosphor}

\section{$2.1 \mathrm{Ca}_{3} \mathrm{Sc}_{2} \mathrm{Si}_{3} \mathrm{O}_{12}: \mathrm{Ce}$}

A green phosphor $\mathrm{Ca}_{3} \mathrm{Sc}_{2} \mathrm{Si}_{3} \mathrm{O}_{12}$ : $\mathrm{Ce}$ has been developed as a phosphor excitable by the blue LED light and emits strong green light for white $\mathrm{LEDs}^{1{ }^{12)} \text {. }}$ Although $\mathrm{Ce}^{3+}$ is activated as a trivalent ion, the replacing site in the garnet host crystal $\mathrm{Ca}_{3} \mathrm{Sc}_{2} \mathrm{Si}_{3} \mathrm{O}_{12}$ is not the trivalent $\mathrm{Sc}^{3+}$ site but the $\mathrm{Ca}^{2+}$ site where an

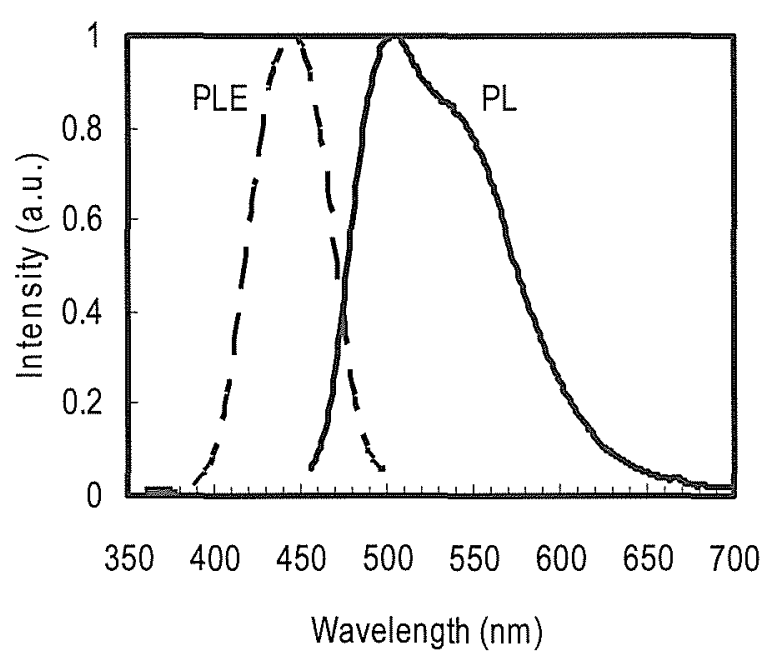

Figure 1 Excitation and Emission Spectra of $\mathrm{Ca}_{3} \mathrm{Sc}_{2} \mathrm{Si}_{3} \mathrm{O}_{12}: \mathrm{Ce}$

Peak wavelength of the excitation spectrum (PLE) is $450 \mathrm{~nm}$, while the peak wavelength of the emission spectrum (PL) is $505 \mathrm{~nm}$. Emission shoulder is observed around 545 nm.

ionic radius is close to each other.

As shown in Figure 1, this phosphor can be efficiently excited by the blue LED light with the emission peak at $450 \mathrm{~nm}$, and emits not only a blue-green light at the peak wavelength of $505 \mathrm{~nm}$ but a green light at the peak wavelengths of $545 \mathrm{~nm}$ corresponding to the energy transition to the two energy levels ${ }^{2} \mathrm{~F}_{7 / 2}$ and ${ }^{2 \mathrm{~F}_{5 / 2}}$ of $\mathrm{Ce}^{3+}$. If this phosphor is used with the blue LED and a proper red phosphor, a good white LED for a lighting with high brightness and good color rendering can be obtained. 


\section{$2.2 \mathrm{Ca}_{3}(\mathrm{Sc}, \mathrm{Mg})_{2} \mathrm{Si}_{3} \mathrm{O}_{12}: \mathrm{Ce}$}

Since the $545 \mathrm{~nm}$ green light component increases as shown in Figure 2 when $\mathrm{Mg}^{2+}$ replaces a part of $\mathrm{Sc}^{3+}$ in this green phosphor, its brightness improves by $25 \%$. In the newly developed green phosphor $\mathrm{Ca}_{3}(\mathrm{Sc}, \mathrm{Mg})_{2} \mathrm{Si}_{3} \mathrm{O}_{12}: \mathrm{Ce}$, the amount of $\mathrm{Mg}^{2+}$ replacing a part of $\mathrm{Sc}^{3+}$ is almost the same as that of $\mathrm{Ce}^{3+} \mathrm{re}^{-}$ placing a part of $\mathrm{Ca}^{2+}$ for the charge compensation.

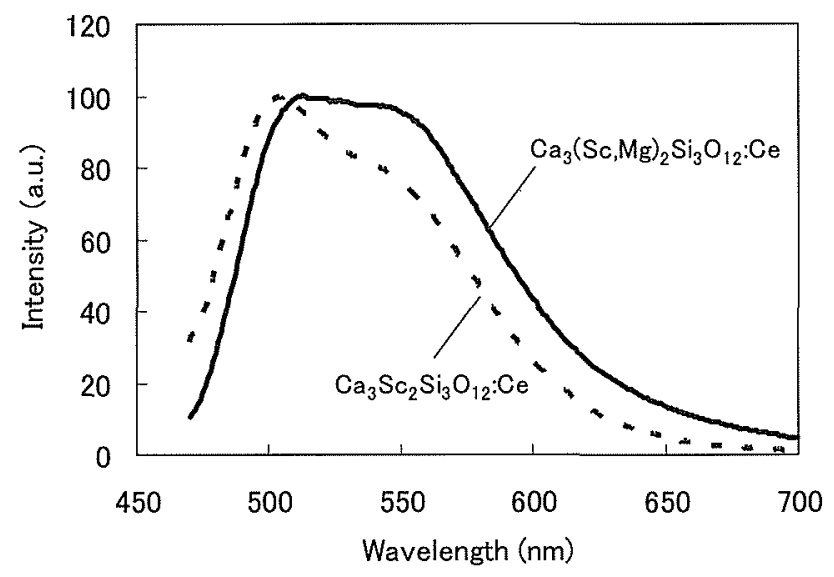

Figure 2 Emission Spectra of $\mathrm{Ca}_{3} \mathrm{Sc}_{2} \mathrm{Si}_{3} \mathrm{O}_{12}$ : $\mathrm{Ce}$ and $\mathrm{Ca}_{3}(\mathrm{Sc}, \mathrm{Mg})_{2} \mathrm{Si}_{3} \mathrm{O}_{12}: \mathrm{Ce}$

$\mathrm{Mg}^{2+}$ substitution for $\mathrm{Sc}^{3+}$ increases the green emission around $545 \mathrm{~nm}$ and its brightness. Excitation wavelength is 455 $\mathrm{nm}$.

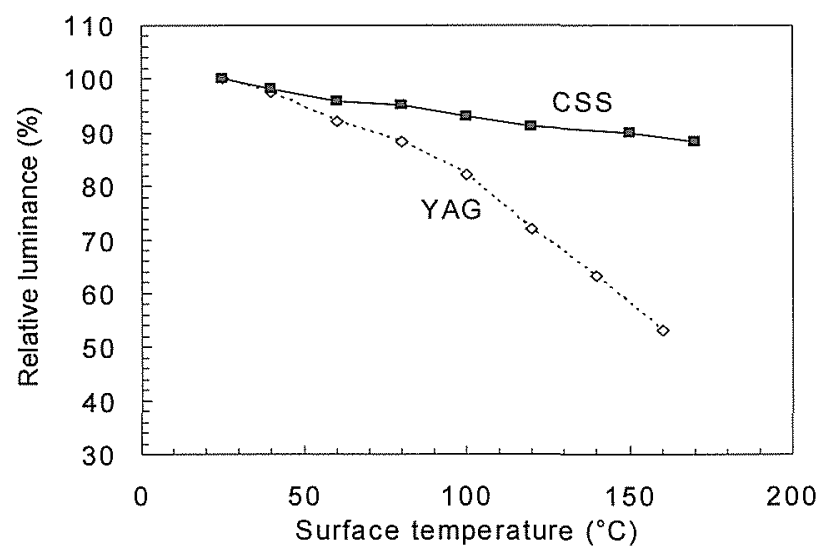

Figure 3 Temperature Characteristics of $\mathrm{Ca}_{3} \mathrm{Sc}_{2} \mathrm{Si}_{3} \mathrm{O}_{12}: \mathrm{Ce}(\mathrm{CSS})$ and $(\mathrm{Y}, \mathrm{Gd})_{3} \mathrm{Al}_{5} \mathrm{O}_{12}: \mathrm{Ce}$ (YAG)

Relative luminance was measured under the excitation light with the wavelength of $455 \mathrm{~nm}$.

The temperature quenching is small in any of $\mathrm{Ca}_{3} \mathrm{Sc}_{2} \mathrm{Si}_{3} \mathrm{O}_{12}$ :Ce and $\mathrm{Ca}_{3}(\mathrm{Sc}, \mathrm{Mg})_{2} \mathrm{Si}_{3} \mathrm{O}_{12}$ :Ce as shown in Figure 3, meaning that the fall of brightness while elevating temperature of a phosphor is small when it is used in a high-power white LED at a high temperature around $100{ }^{\circ} \mathrm{C}$. Therefore, the color of the white LED does not change as much as in the white
LED with the YAG yellow phosphor of which temperature quenching is larger than $\mathrm{Ca}_{3} \mathrm{Sc}_{2} \mathrm{Si}_{3} \mathrm{O}_{12}: \mathrm{Ce}$ and $\mathrm{Ca}_{3}(\mathrm{Sc}, \mathrm{Mg})_{2} \mathrm{Si}_{3} \mathrm{O}_{12}: \mathrm{Ce}$.

\section{$2.3 \mathrm{CaSc}_{2} \mathrm{O}_{4}: \mathrm{Ce}$}

Another new oxide bright green phosphor $\mathrm{CaSc}_{2} \mathrm{O}_{4}: \mathrm{Ce}$ has been discovered ${ }^{33}$.

Its host crystal $\mathrm{CaSc}_{2} \mathrm{O}_{4}$ has an orthorhombic $\mathrm{CaFe}_{2} \mathrm{O}_{4}$ structure. In $\mathrm{CaSc}_{2} \mathrm{O}_{4}: \mathrm{Ce}$, the activator ion $\mathrm{Ce}^{3+}$ replaces a part of $\mathrm{Ca}^{2+}$ instead of $\mathrm{Sc}^{3+}$ as in $\mathrm{Ca}_{3} \mathrm{Sc}_{2} \mathrm{Si}_{3} \mathrm{O}_{12}$ :Ce.

This new phosphor has an excitation peak at 450 nm like $\mathrm{Ca}_{3} \mathrm{Sc}_{2} \mathrm{Si}_{3} \mathrm{O}_{12}: \mathrm{Ce}$. As shown in Figure 4 and Figure 5, it has an emission spectrum similar to $\mathrm{Ca}_{3} \mathrm{Sc}_{2} \mathrm{Si}_{3} \mathrm{O}_{12}:$ Ce. Emission peak is at $515 \mathrm{~nm}$, a little longer than $\mathrm{Ca}_{3} \mathrm{Sc}_{2} \mathrm{Si}_{3} \mathrm{O}_{12}$ :Ce.

If $\mathrm{Mg}^{2+}$ replaces a part of $\mathrm{Sc}^{3+}$ in $\mathrm{CaSc}_{2} \mathrm{O}_{4}$ : $\mathrm{Ce}$, the emission peak wavelength increases as in $\mathrm{Ca}_{3} \mathrm{Sc}_{2} \mathrm{Si}_{3} \mathrm{O}_{12}$ :Ce. On the other hand, if a part of $\mathrm{Ca}^{2+}$ is replaced by $\mathrm{Sr}^{2+}$, the emission peak shifts to the shorter wavelength.

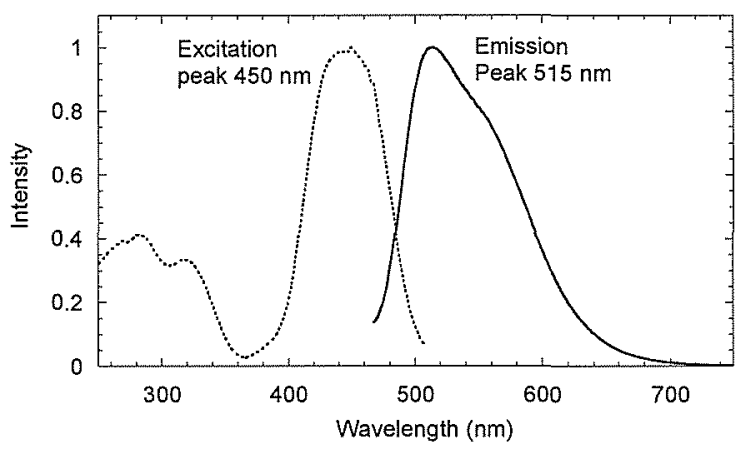

Figure 4 Excitation and Emission Spectra of $\mathrm{CaSc}_{2} \mathrm{O}_{4}: \mathrm{Ce}^{3+}$

Peak wavelength of the excitation spectrum is $450 \mathrm{~nm}$, while the peak wavelength of the emission spectrum is $515 \mathrm{~nm}$.

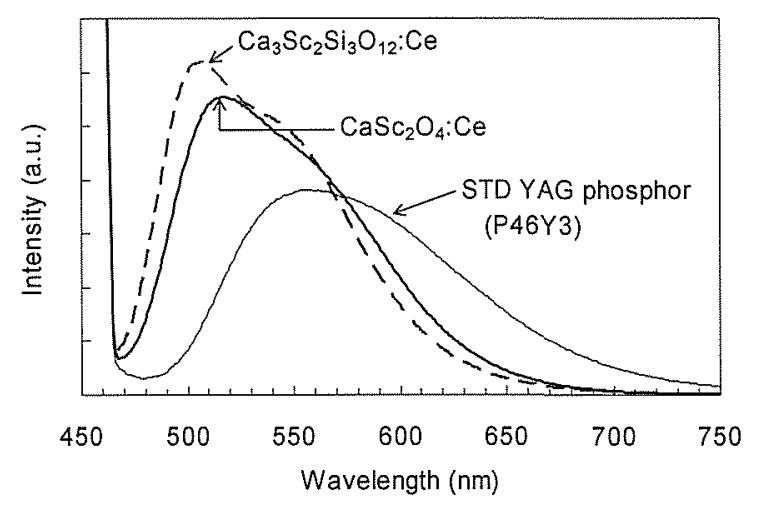

Figure 5 Comparison of Emission Spectra of Two Sc-based Oxide Phosphors and YAG Two Sc-based phosphors have very similar emission spectra. Excitation wavelength is $455 \mathrm{~nm}$. 
Since $\mathrm{CaSc}_{2} \mathrm{O}_{4}: \mathrm{Ce}$ also shows small temperature quenching, when the phosphor is used in a high-power white LED, a color shift of the LED due to the decrease of the brightness of the phosphor at high temperature is small.

\section{$2.4 \mathrm{Ba}_{3} \mathrm{Si}_{6} \mathrm{O}_{12} \mathrm{~N}_{2}: \mathrm{Eu}$}

A new oxinitride high-luminous green phosphor $\mathrm{Ba}_{3} \mathrm{Si}_{6} \mathrm{O}_{12} \mathrm{~N}_{2}: \mathrm{Eu}$ excitable under near ultraviolet light and blue light has been discovered ${ }^{4}$.

The host crystal of this phosphor has a new trigonal crystal structure. It belongs to the space group $P \overline{3}$, and its lattice constants are $a=750.46(8)$ $\mathrm{pm}$ and $c=647.03(5) \mathrm{pm}$. Eu occupies at the Ba site coordinated by six oxygen atoms and a nitrogen atom.

Figure 6 shows the excitation and emission spectra of $\mathrm{Ba}_{3} \mathrm{Si}_{6} \mathrm{O}_{12} \mathrm{~N}_{2}: \mathrm{Eu}$. The broad excitation band observed from $250 \mathrm{~nm}$ to $500 \mathrm{~nm}$ is assigned to the allowed transition from $4 \mathrm{f}^{7}$ grand state to $4 \mathrm{f}^{6} 5 \mathrm{~d}$ state of $\mathrm{Eu}^{2+}$. On the other hand, the green emission spectrum with FWHM of $68 \mathrm{~nm}$ is observed at $525 \mathrm{~nm}$ due to the $5 \mathrm{~d}-4 \mathrm{f}$ transition of $\mathrm{Eu}^{2+}$.

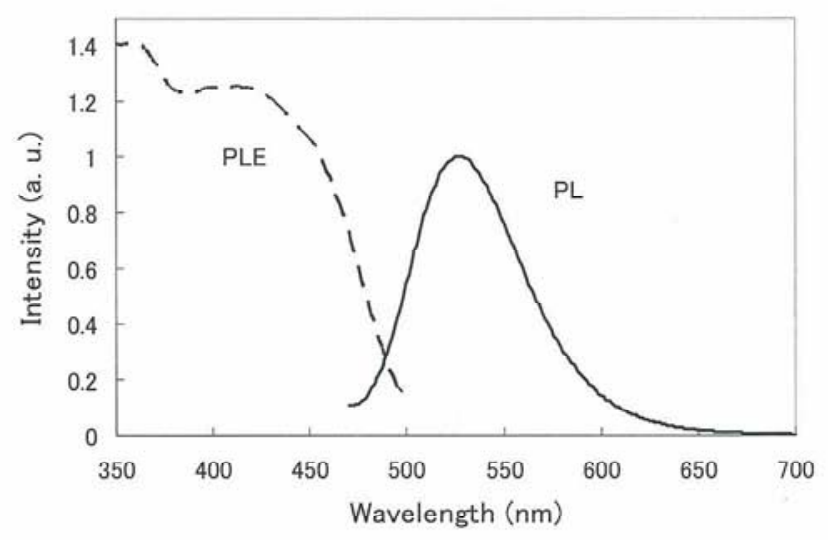

Figure 6 Excitation spectrum (PLE) and emission spectrum (PL) of $\mathrm{Ba}_{3} \mathrm{Si}_{6} \mathrm{O}_{12} \mathrm{~N}_{2}$ : Eu Excitation spectrum was obtained by monitoring emission at $525 \mathrm{~nm}$. For the emission spectrum, the wavelength of the excitation light was set at $455 \mathrm{~nm}$.

$\mathrm{Ba}_{3} \mathrm{Si}_{6} \mathrm{O}_{12} \mathrm{~N}_{2}: \mathrm{Eu}$ has an efficient green emission under near UV or blue LED light. The phosphor is suitable for LED backlight in LCD owing to exhibiting the higher green color purity with the CIE color coordinates $(\mathrm{x}, \mathrm{y})$ of 0.274 and 0.644 which is similar to those of $(\mathrm{Ba}, \mathrm{Sr})_{2} \mathrm{SiO}_{4}: \mathrm{Eu}$.

As shown in Figure 7, the new green phosphor $\mathrm{Ba}_{3} \mathrm{Si}_{6} \mathrm{O}_{12} \mathrm{~N}_{2}$ :Eu has much smaller thermal quenching than $(\mathrm{Ba}, \mathrm{Sr})_{2} \mathrm{SiO}_{4}: \mathrm{Eu}$. Therefore, the new green phosphor is better than $(\mathrm{Ba}, \mathrm{Sr})_{2} \mathrm{SiO}_{4}: \mathrm{Eu}$ for high-power white LEDs.

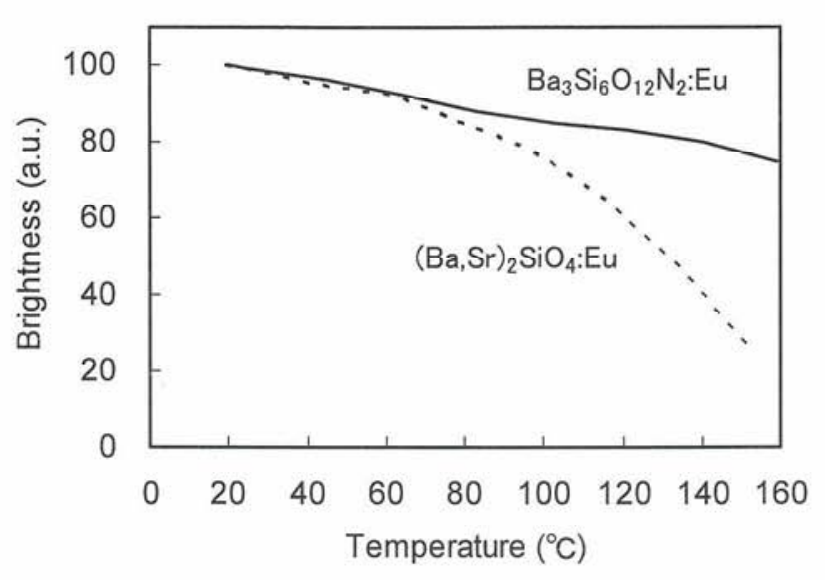

Figure 7 Temperature Quenching of $\mathrm{Ba}_{3} \mathrm{Si}_{6} \mathrm{O}_{12} \mathrm{~N}_{2}: \mathrm{Eu}$ and $(\mathrm{Ba}, \mathrm{Sr})_{2} \mathrm{SiO}_{4}: \mathrm{Eu}$

\section{Red phosphor}

\section{$3.1 \mathrm{CaAlSiN}_{3}: \mathrm{Eu}$}

$\mathrm{CaAlSiN}_{3}: \mathrm{Eu}$ phosphor has been developed as a red phosphor for a white LED ${ }^{5}$. This phosphor emits strong red light with a wideband of about $90 \mathrm{~nm}$ in FWHM and the emission peak at $650 \mathrm{~nm}$ in wavelength, as shown in Figure 8.

The emission spectrum of $\mathrm{CaAlSiN}_{3}: \mathrm{Eu}$ is similar to that of a sulfide red phosphor $(\mathrm{Ca}, \mathrm{Sr}) \mathrm{S}: \mathrm{Eu}$. Since $\mathrm{CaAlSiN}_{3}: \mathrm{Eu}$ is stable in the ambient atmosphere without decomposing with moisture in the air unlike $(\mathrm{Ca}, \mathrm{Sr}) \mathrm{S}: \mathrm{Eu}$, a special caution about atmosphere control is not necessary when a white LED is produced with $\mathrm{CaAlSiN}_{3}: \mathrm{Eu}$.

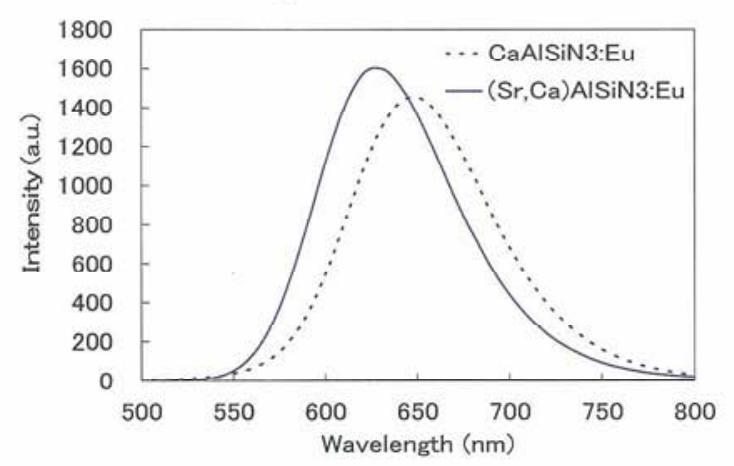

Figure 8 Emission Spectra of $\mathrm{CaAISiN}_{3}$ :Eu and $(\mathrm{Sr}, \mathrm{Ca}) \mathrm{AlSiN}_{3}$ :Eu $\mathrm{CaAISiN}_{3}: \mathrm{Eu}$ and $(\mathrm{Sr}, \mathrm{Ca}) \mathrm{AISiN}_{3}: \mathrm{Eu}$ have the emission peaks at $650 \mathrm{~nm}$ and $628 \mathrm{~nm}$, respectively. The wavelength of the excitation light is $455 \mathrm{~nm}$.

\section{$3.2(\mathrm{Sr}, \mathrm{Ca}) \mathrm{AlSiN}_{3}: \mathrm{Eu}$}

If $\mathrm{Ca}^{2+}$ of $\mathrm{CaAlSiN}_{3}: \mathrm{Eu}$ is replaced by $\mathrm{Sr}^{2+}$, the emission peak shifts to the shorter wavelength where the eye sensitivity is higher than that at the emission peak about $650 \mathrm{~nm}$ of $\mathrm{CaAlSiN}_{3}: \mathrm{Eu}$. $(\mathrm{Sr}, \mathrm{Ca}) \mathrm{AlSiN}_{3}$ :Eu with much higher brightness than 
$\mathrm{CaAlSiN}_{3}$ : $\mathrm{Eu}$ has been newly developed by controlling the oxygen concentration in the host crystal as small as possible through optimizing a manufacturing process using $\mathrm{Sr}^{-} \mathrm{Ca}-\mathrm{Al}-\mathrm{Si}-\mathrm{Eu}$ alloy to increase the emission intensity. By replacing $80 \%$ of $\mathrm{Ca}^{2+}$ by $\mathrm{Sr}^{2+}$, the emission peak wavelength shifts to $628 \mathrm{~nm}$ as shown in Fig. 8, and the brightness becomes approximately twice as high as that of CaAlSiNs: $\mathrm{Eu}$.

The excitation spectrum of $(\mathrm{Sr}, \mathrm{Ca}) \mathrm{AlSiN}_{3}: \mathrm{Eu}$ is similar to that of $\mathrm{CaAlSiN}_{3}: \mathrm{Eu}$ as shown in Figure 9. It is excited by a blue LED with an emission peak wavelength of about $450 \mathrm{~nm}$. It is also strongly ex* cited by a near-ultraviolet LED with the emission peak wavelength of about $400 \mathrm{~nm}$. Moreover, since the excitation band is very broad, it is stably excited and almost the same luminescent intensity can be obtained, even if the emission wavelength of the LED which is a source of excitation light shifts somewhat.

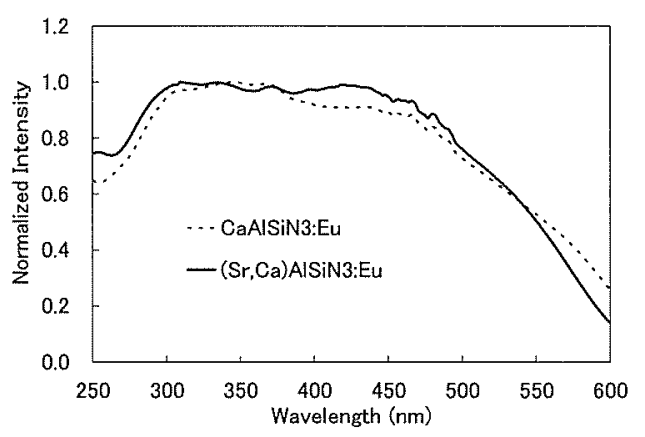

Figure 9 Excitation Spectra of $\mathrm{CaAlSiN}_{3}: \mathrm{Eu}$ and (Sr, Ca)AISiN ${ }_{3}: \mathrm{Eu}$

Both $\mathrm{CaAlSiN}_{3}: \mathrm{Eu}$ and (Sr,Ca)AISiN $\mathrm{N}_{3}: \mathrm{Eu}$ have broad excitation bands from 300 $\mathrm{nm}$ to $500 \mathrm{~nm}$. The intensity was measured at the emission peak wavelength of each phosphor.

If this red phosphor is used combining with a blue LED and a green phosphor, it will become possible to make a white LED with good color-rendering and very high brightness. Such a white LED can be used as a light source for a good color-rendering lighting or for an LCD with a good color reproducibility.

The temperature quenching of the red phosphors is smaller than that of the YAG yellow phosphor and the sulfide red phosphor $(\mathrm{Ca}, \mathrm{Sr}) \mathrm{S}: \mathrm{Eu}$, and still smaller than that of another nitride red phosphor $\mathrm{Ca}_{2} \mathrm{Si}_{5} \mathrm{~N}_{8}: \mathrm{Eu}^{5}$ ) Therefore, when used as a phosphor for a high-power white LED, even if the temperature of a phosphor rises, there is little temperature quenching of the phosphor, and there is little color shift of a white LED due to the unbalance of the light mixture of the transparent light from a blue
LED and the fluorescent light from the phosphor.

Like the sulfide red phosphor ( $\mathrm{Ca}, \mathrm{Sr}) \mathrm{S}: \mathrm{Eu}$ and the nitride red phosphor $\mathrm{Ca}_{2} \mathrm{Si}_{5} \mathrm{~N}_{8}: \mathrm{Eu}, \mathrm{CaAlSiN}_{3}: \mathrm{Eu}$ and $(\mathrm{Sr}, \mathrm{Ca}) \mathrm{AlSiN}_{3}: \mathrm{Eu}$ are excited by not only the blue LED light but the fluorescent light from the green phosphor excited by the blue LED. This excitation mechanism reduces the luminous efficacy of the white LED if the white LED is made by the way that these green and red phosphors are blended on the blue LED as the excitation light source. In order to obtain an efficient white LED, it is necessary to choose a separate configuration of two or more phosphors appropriately.

\section{Characteristics of white light emitting diode}

\subsection{White LED for Lighting}

A blue LED chip with the emission peak wavelength of $455 \mathrm{~nm}$ is set to the bottom of a package for a surface mounting device (SMD) as a light source of excitation. The emission spectrum of the white LED made by applying on the blue LED chip the mixture of silicone resin, the green phosphor $\mathrm{Ca}_{3} \mathrm{Sc}_{2} \mathrm{Si}_{3} \mathrm{O}_{12}: \mathrm{Ce}$, and the red phosphor $\mathrm{CaAlSiN}_{3}: \mathrm{Eu}$ is shown in Figure 10. Since the emission of the blue LED, the green phosphor, and the red phosphor makes a comparatively flat continuous spectrum, the average color rendering index $\mathrm{Ra}$ of the white LED becomes 90 . Its color coordinates are $x=0.32$ and $y=$ 0.33 .

Another emission spectrum of a white LED similarly obtained by combining a blue LED chip, the green phosphor $\mathrm{CaSc}_{2} \mathrm{O}_{4}: \mathrm{Ce}$, and the red phosphor $\mathrm{CaAlSiN}_{3}: \mathrm{Eu}$ is shown in Figure 11. Its color coordinates are $x=0.31$ and $y=0.31$, and its average color rendering index $\mathrm{Ra}$ is 91 .

Similarly, a white LED with a good color rendering property and high luminance can be obtained also by combining the red phosphor $(\mathrm{Sr}, \mathrm{Ca}) \mathrm{AlSiN}_{3}: \mathrm{Eu}$ with a blue LED chip and the green phosphor $\mathrm{CaSc}_{2} \mathrm{O}_{4}$ :Ce.

\subsection{White LED for Display}

Since the emission band of the YAG phosphor is broad, the luminous efficacy of the light which penetrates color filters does not become high in using a white LED as a back-light source for LCDs. For this reason, an $\mathrm{Eu}^{2+-a c t i v a t e d}$ green phosphor such as $(\mathrm{Ba}, \mathrm{Sr})_{2} \mathrm{SiO}_{4}$ :Eu or $\mathrm{Ba}_{3} \mathrm{Si}_{6} \mathrm{O}_{12} \mathrm{~N}_{2}$ :Eu with a comparatively narrowband emission should be used with the red phosphor $\mathrm{CaAlSiN}_{3}$ :Eu in this application.

Figure 12 and Figure 13 show the emission spectra of white LEDs with the combination of blue LED chips, (Ba,Sr) ${ }_{2} \mathrm{SiO}_{4}: \mathrm{Eu}$ or $\mathrm{Ba}_{3} \mathrm{Si}_{6} \mathrm{O}_{12} \mathrm{~N}_{2}: \mathrm{Eu}$ as a green phosphor, and red phosphor $\mathrm{CaAlSiN}_{3}: \mathrm{Eu}$. In the both emission spectra, the emission peaks of three colors of blue, green, and red light comparatively separate as compared with a white LED with the 


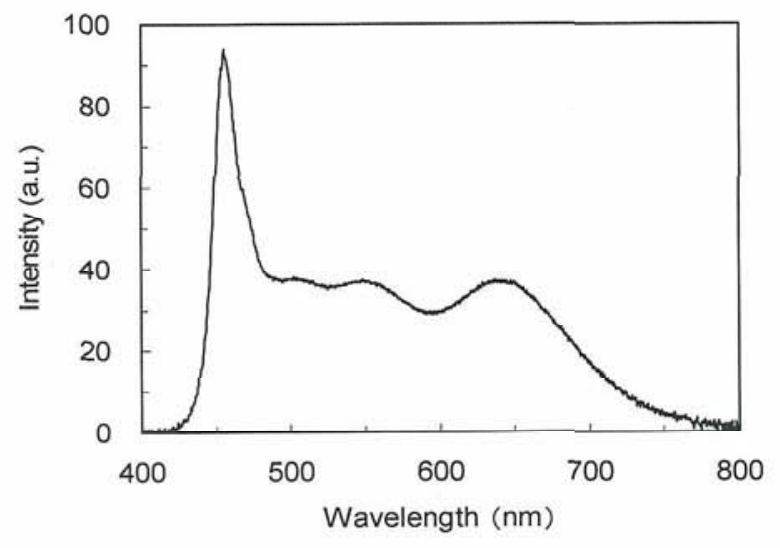

Figure 10 Emission Spectrum of a White LED for Lighting

A blue LED chip with the emission peak wavelength of $455 \mathrm{~nm}$, silicone resin, green phosphor $\mathrm{Ca}_{3} \mathrm{Sc}_{2} \mathrm{Si}_{3} \mathrm{O}_{12}: \mathrm{Ce}$ and red phosphor $\mathrm{CaAISiN}_{3}$ :Eu are used to make an SMD type white LED.

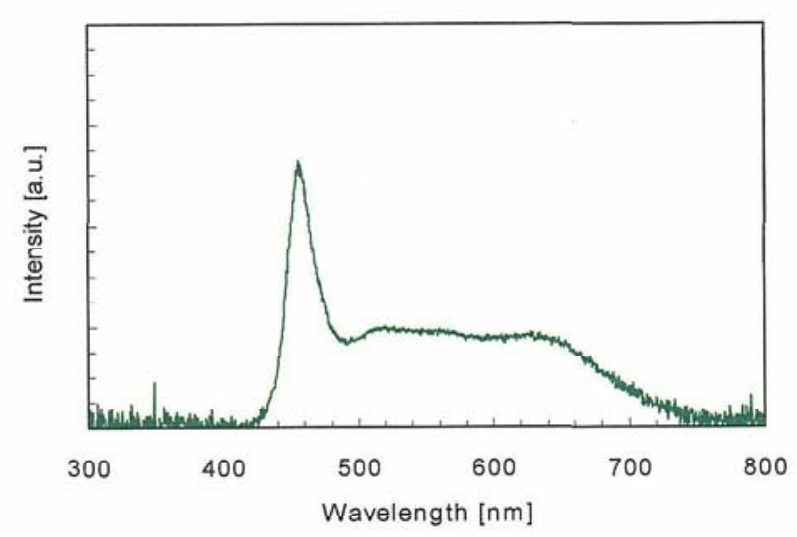

Figure 11 Emission Spectrum of a White LED for Lighting

A blue LED chip with the emission peak wavelength of $455 \mathrm{~nm}$, silicone resin, green phosphor $\mathrm{CaSc}_{2} \mathrm{O}_{4}: \mathrm{Ce}$ and red phosphor $\mathrm{CaAISiN}_{3}: \mathrm{Eu}$ are used.

combination of a blue LED chip and yellow phosphor YAG. After penetrating proper color filters, the luminous efficacy of the light from the white LED using a green phosphor $(\mathrm{Ba}, \mathrm{Sr})_{2} \mathrm{SiO}_{4}: \mathrm{Eu}$ or $\mathrm{Ba}_{3} \mathrm{Si}_{6} \mathrm{O}_{12} \mathrm{~N}_{2}: \mathrm{Eu}$ and the red phosphor $\mathrm{CaAlSiN}_{3}: \mathrm{Eu}$ becomes about $30 \%$ higher than that using YAG. Thus, as a light source for LCDs, a white LED obtained by combining the green phosphor $\left(\mathrm{Ba}, \mathrm{Sr}_{2}\right)_{2} \mathrm{SiO}_{4}: \mathrm{Eu}$ or $\mathrm{Ba}_{3} \mathrm{Si}_{6} \mathrm{O}_{12} \mathrm{~N}_{2}: \mathrm{Eu}$ and the red phosphor $\mathrm{CaAlSiN}_{3}: \mathrm{Eu}$ is clearly advantageous with respect to the luminous efficacy.

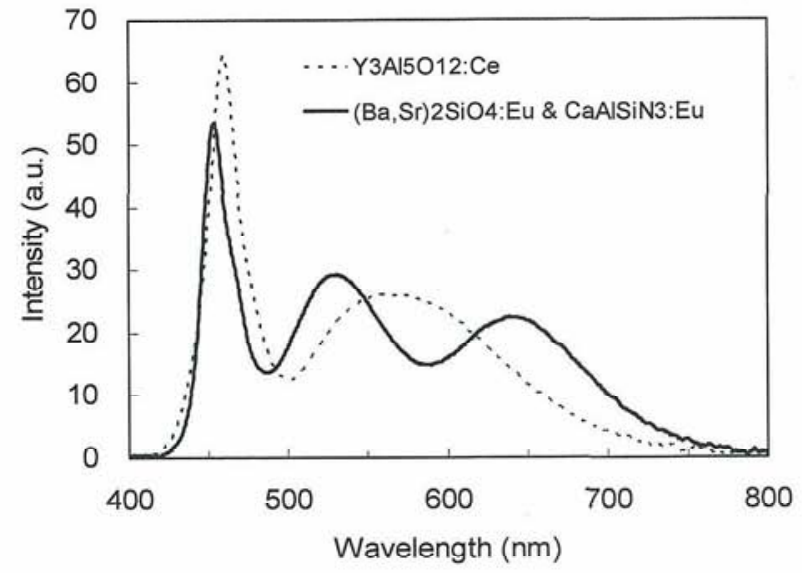

Figure 12 Emission Spectra of White LEDs for Liquid Crystal Displays

A blue LED chip with the emission peak wavelength of $455 \mathrm{~nm}$, silicone resin, green phosphor $(\mathrm{Ba}, \mathrm{Sr})_{2} \mathrm{SiO}_{4}: \mathrm{Eu}$ and red phosphor $\mathrm{CaAISiN}_{3}: \mathrm{Eu}$ are used to make a white LED, comparing with a white LED using a blue LED and $(\mathrm{Y}, \mathrm{Gd})_{3} \mathrm{Al}_{5} \mathrm{O}_{12}: \mathrm{Ce}$.

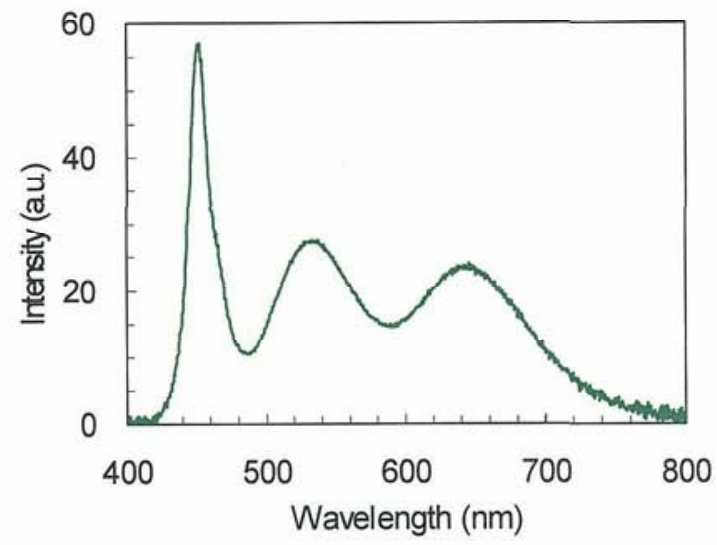

Figure 13 Emission Spectra of White LEDs for Liquid Crystal Displays

A blue LED chip with the emission peak wavelength of $455 \mathrm{~nm}$, silicone resin, the new green phosphor $\mathrm{Ba}_{3} \mathrm{Si}_{6} \mathrm{O}_{12} \mathrm{~N}_{2}$ : Eu and red phosphor $\mathrm{CaAISiN}_{3}: \mathrm{Eu}$ are used to make a white LED.

\section{Conclusions}

New green phosphors $\mathrm{Ca}_{3}\left(\mathrm{Sc}, \mathrm{Mg}_{2} \mathrm{Si}_{3} \mathrm{O}_{12}: \mathrm{Ce}\right.$, $\mathrm{CaSc}_{2} \mathrm{O}_{4}: \mathrm{Ce}, \mathrm{Ba}_{3} \mathrm{Si}_{6} \mathrm{O}_{12} \mathrm{~N}_{2}: \mathrm{Eu}$, and a red phosphor $(\mathrm{Sr}, \mathrm{Ca}) \mathrm{AlSiN}_{3}: \mathrm{Eu}$ have been developed for white LEDs. All the phosphors are suitable for high-power white LEDs since they have high luminous efficacy and show small thermal quenching.

A white LED obtained by combining a blue LED chip, one of the green phosphors $\mathrm{Ca}_{3} \mathrm{Sc}_{2} \mathrm{Si}_{3} \mathrm{O}_{12}: \mathrm{Ce}$, $\mathrm{Ca}_{3}(\mathrm{Sc}, \mathrm{Mg})_{2} \mathrm{Si}_{3} \mathrm{O}_{12}: \mathrm{Ce}$ or $\mathrm{CaSc}_{2} \mathrm{O}_{4}: \mathrm{Ce}$, and one of the red phosphors $\mathrm{CaAlSiN}_{3}: \mathrm{Eu}$ or $(\mathrm{Sr}, \mathrm{Ca}) \mathrm{AlSiN}_{3}: \mathrm{Eu}$ has 
shown high brightness and good color rendering.

On the other hand, a white LED obtained with a blue LED chip, one of the green phosphors $(\mathrm{Ba}, \mathrm{Sr})_{2} \mathrm{SiO}_{4}: \mathrm{Eu}$ or $\mathrm{Ba}_{3} \mathrm{Si}_{6} \mathrm{O}_{12} \mathrm{~N}_{2}: \mathrm{Eu}$, and the red phosphor $\mathrm{CaAlSiN}_{3}$ :Eu is advantageous with respect to the luminous efficacy and color reproducibility as a light source for LCDs.

\section{References}

(1) Y. Shimomura and N. Kijima: Proc. of the $65^{\text {th }}$ Meeting of Japan Society of Applied Physics, p.1284 (2004).

(2) Y. Shimomura, T. Honma, M. Shigeiwa, T. Akai, K. Okamoto, and N. Kijima: J. Electrochem. Soc., 154 (1) (2007) J35-J38.
(3) Y. Shimomura, T. Kurushima, and N. Kijima: J. Electrochem. Soc., 154 (8) (2007) J234-J238.

(4) S. Shimooka, K. Uheda, M. Mikami, N. Kijima, $\mathrm{H}$. Imura, and K. Horibe: PCT WO $2007 / 088966$.

(5) K. Uheda, N. Hirosaki, Y. Yamamoto, A. Naito, T. Nakajima, and H. Yamamoto: Electrochemical and Solid-State Letters, 9 (4) (2006) $\mathrm{H} 22-\mathrm{H} 25$.

This paper is based on the authors' presentation given at the 1st International Conference on White LEDs and Solid State Lighting held in Tokyo, Japan, on November 26th - 30th, 2007. 